\title{
COMPARATIVE ANALYSIS OF VARIOUS CAMERA INPUT FOR VIDEOGRAMMETRY
}

\author{
Ahmad, N. ${ }^{1}$, Azri, S. ${ }^{1}$, Ujang, U. ${ }^{1}$, Cuétara,M.G. ${ }^{2}$, Retortillo,G.M. ${ }^{2}$ and Mohd Salleh, S. ${ }^{1}$ \\ ${ }^{1}$ Dep. of Geoinformation, Faculty of Built Environment and Surveying, Universiti Teknology Malaysia (UTM), Johor, Malaysia \\ noorulya2@live.utm.my, suhaibah@utm.my,mduznir@utm.my, syahiirahsalleh78@gmail.com \\ ${ }^{2}$ Planta 5 a Oficina 16, Calle Luis Álvarez Lencero, 3, 06011 Badajoz, Spain \\ ceo@ecapture3d.com, guillermo@ecapture3d.com
}

KEY WORDS: Videogrammetry, camera, point clouds, 3D model

\begin{abstract}
:
Videogrammetry is a technique to generate point clouds by using video frame sequences. It is a branch of photogrammetry that offers an attractive capabilities and make it an interesting choice for a 3D data acquisition. However, different camera input and specification will produce different quality of point cloud. Thus, it is the aim of this study to investigate the quality of point cloud that is produced from various camera input and specification. Several devices are using in this study such as Iphone 5s, Iphone 7+, Iphone X, Digital camera of Casio Exilim EX-ZR1000 and Nikon D7000 DSLR. For each device, different camera with different resolution and frame per second (fps) are used for video recording. The videos are processed using EyesCloud3D by eCapture. EyesCloud3D is a platform that receive input such as videos and images to generate point clouds. 3D model is constructed based on generated point clouds. The total number of point clouds produced is analyzed to determine which camera input and specification produce a good 3D model. Besides that, factor of generating number of point clouds is analyzed. Finally, each camera resolution and fps is suggested for certain applications based on generated number of point cloud.
\end{abstract}

\section{INTRODUCTION}

Videogrammetry is a technique to represent an object in threedimensional (3D) and using videos as data input. This technique can be used to collect spatial data by using several type of cameras. The coordinates of $\mathrm{x}, \mathrm{y}$ and height $(\mathrm{z})$ points will be produced from the video to produce three-dimensional (3D) objects, different angle of the object in the videos are required. Generally, the method for this technique is based on number of images or videos that been captured using certain camera. It is very time consuming because the user has to move the camera while scanning the object or building in the scene so that the progress of the scene can be updated especially in the construction area (Brilakis, Fathi, \& Rashidi, 2011). According to Rashidi, Dai, Brilakis, \& Vela (2013), information from video is more valuable and more information can be attracted compared to static images. It is also easier to process.

Videogrammetry technique is considered as low cost technique and easy to use to produce a three-dimensional (3D) model. This technique can help in the collecting of spatial data and it will be useful for user that require spatial data for their work and projects (Keling et. al. 2017; Azri et. al 2015; Mohd et. al. 2016; Ujang et. al. 2018). Engineers that are a leader in some project will cooperate with the architecture and also person in charge in construction, therefore, videogrammetry will help them to monitor and control the issues or any updates from the construction projects quickly because the result will be in threedimensional (3D) model (i.e. Mohd et. al. 2017). Other than that, they can work in designing the site layout more systematically or if there are disaster in that particular area, they can use this technique to access the damage by using the video streams (videogrammetry) from the scene (Rashidi et al., 2013)

However, there are some challenges in using videogrammetry such as the nature of time sensitivity and also the automation level involved (Brilakis et al., 2011). There are also some major issues that need to be emphasized such as poor quality in capturing the images of video during scanning the objects at the scene. It is difficult to control the environment and camera factors such as the camera speed that will cause the motion blur, the condition of the light from the area or the resolution of the camera and the storage of the memory in the camera (Rashidi et al., 2013).

Therefore, this research will study the camera specification for videogrammetry, analyse output from each specification of camera and determine applications that are suitable according to the output from the camera specifications.

\section{BACKGROUND}

\subsection{Videogrammetry}

This research attempted to study the differences of the cameras in terms of number of points out of the total of point clouds for each device and determine which device have a better quality. The advantage of the videogrammetry technique is any device can be used especially if the cost in purchasing the devices are low. Most of devices used to produce 3D model are expensive and the skill expertise is needed to manage the device and produce 3D model. Conversely, the videogrammetry technique is very affordable and easy to use (Rashidi, 2014). However, the limitation for this technique is that the result will not be as accurate as photogrammetry because recording a video will produce some noises caused by the weather or movement during recording and also shadow of a model.

Furthermore, videogrammetry is also used for applications such as in manufacturing industry in producing a human face surface for a doll, engineering, security in determining the crime scene and architecture in producing the structures of a building. There are some studies or related research about videogrammetry. The research is about a video mapping system used to change the shape objects that are irregular into a three-dimensional (3D) 
model by capturing all the features of the objects from a moving vehicle (Sharbini, 2013). Other research is using the video camera for virtual three-dimensional (D) city modelling (Singh, Jain, \& Mandla, 2014). Both of these researches related to video recording in producing $3 \mathrm{D}$ model.

In this research, devices that will be use are cameras from smartphone, digital camera and DSLR. All the cameras will get a difference result of total points cloud. According to the difference result of total points cloud, it will help user to know which cameras have a better quality. The cameras will be used to scan or video recording the building model then the result will be show in points cloud and 3D wireframe model.

\subsection{EyesCloud3D and eCapture3D}

eCapture 3D is a company from Spain. This company created a platform for any user to easily produce 3D models. The 3D models can be produced by using images or videos. The eyesCloud3D is a place for users to upload images or videos. Users only have to take several images or record a video by using their own devices such as smartphone, tablets, any types of camera and drone. Then, the images or videos will be uploaded into the eyesCloud3D so that the 3D model can be generated.

\section{METHODOLOGY}

\subsection{Tools}

In order to produce point clouds, five types of camera were used in this study which consists of smartphones, digital camera and digital single-lens reflex camera (DSLR) as shown in Figure 1. The specification of the camera which includes the resolution and frame per second (fps) is shown in Table 1. Each camera will be used to take video recording of a model according to their specifications.

\begin{tabular}{|c|c|c|}
\hline Camera & Resolution & Frame per second (fps) \\
\hline Iphone 5s & $1080 \mathrm{p}$ & $30 \mathrm{fps}$ \\
\hline \multirow{2}{*}{ Iphone 7+ } & $1080 \mathrm{p}$ & $30 \mathrm{fps}$ \\
\cline { 2 - 3 } & $1080 \mathrm{p}$ & $60 \mathrm{fps}$ \\
\cline { 2 - 3 } & $4 \mathrm{~K}$ & $30 \mathrm{fps}$ \\
\hline \multirow{2}{*}{ Iphone X } & $1080 \mathrm{p}$ & $30 \mathrm{fps}$ \\
\cline { 2 - 3 } & $1080 \mathrm{p}$ & $60 \mathrm{fps}$ \\
\hline \multirow{2}{*}{$\begin{array}{c}\text { Digital camera } \\
\text { (Casio Exilim) }\end{array}$} & $7 \mathrm{~K}$ & $60 \mathrm{fps}$ \\
\hline $\begin{array}{c}\text { DSLR } \\
\text { (Nikon D7000) }\end{array}$ & $1080 \mathrm{p}$ & $30 \mathrm{fps}$ \\
\hline
\end{tabular}

Table 1. Camera specification

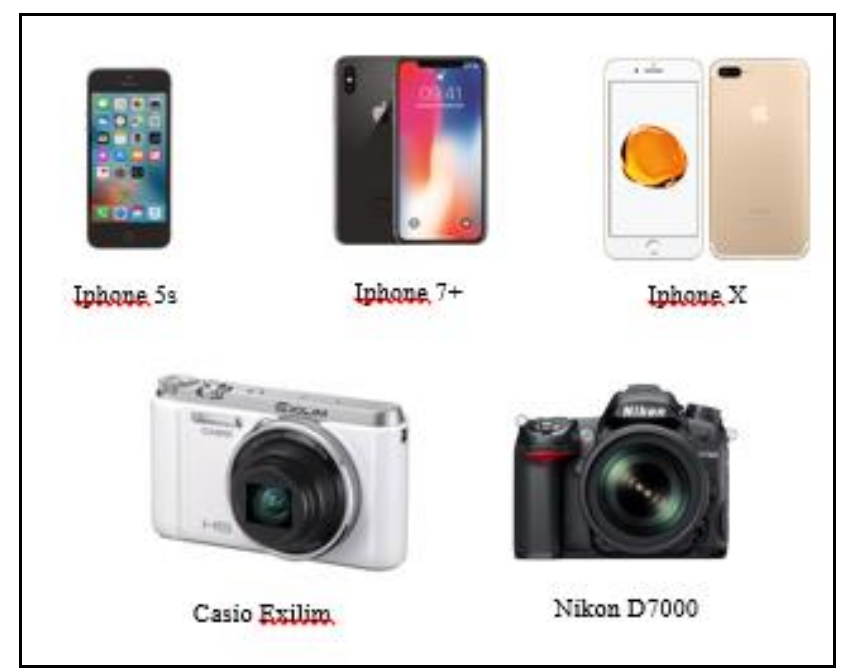

Figure 1. Type of camera

\subsection{Camera Calibration}

The cameras were calibrated according to the specifications. A calibration frame was prepared and 146 markers were set on the model as shown in Figure 2. The markers are used to calculate the distance from one point to another point.

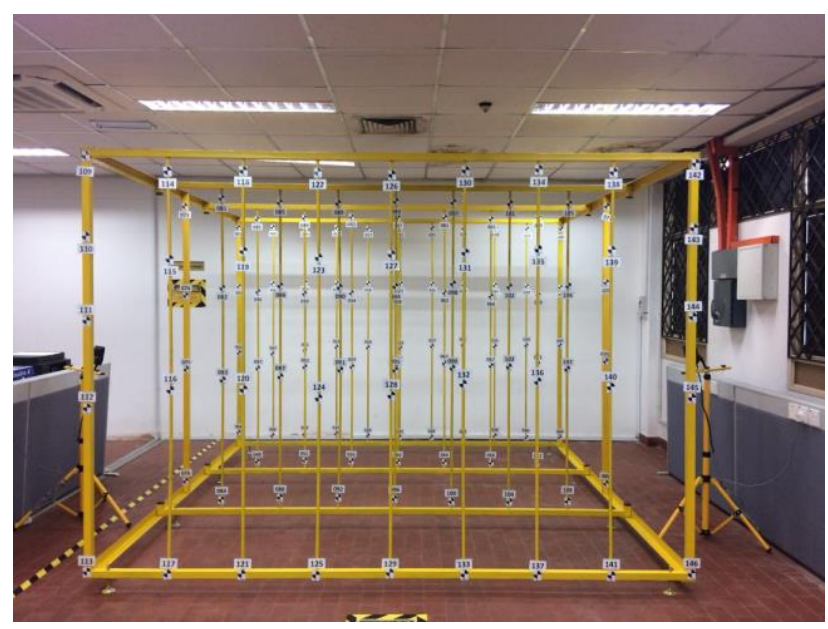

Figure 2.3D calibration frame

A total station is used to calculate the distance of the points. Each point will have their own coordinate values that have been determined by using a total station. The distance was calculated by using the formula of Theorem Pythagoras. The distance between two points in a plane with Cartesian coordinates $\mathrm{A}(\mathrm{x} 1$, $\mathrm{y} 1)$ and $\mathrm{B}(\mathrm{x} 2, \mathrm{y} 2)$ as given in the following formula.

$$
A B=\sqrt{\left(x_{2}-x_{1}\right)^{2}+\left(y_{2}-y_{1}\right)^{2}}
$$

Figure 3. Theorem of Pythagoras

After the coordinates for each point is determined, a video recording from each camera is taken. The video will be processed in EyesCloud3D and point clouds will be generated. EyesCloud3D also provided a measure tool to calculate the distance from one point to another point. Then, the distance measured from total station and measure tool in EyesCloud3D was compared to determine the difference in distance of the cameras using different methods. The distance measure was in meter unit. The difference between total station and point 
clouds was compared using meter and millimeter unit. The comparison distance is in $\mathrm{x}$-axis, $\mathrm{y}$-axis and z-axis. The markers show the two number of points on the calibration model. Any of the markers were chosen to check the distance. The distance was compared with the total station distance and cameras distance minus both distance to get the difference in meter unit then converted into millimeter unit. Table 9, Table 10 and Table 11 show the calibration result and the difference of distance in $\mathrm{x}$-axis, $\mathrm{y}$-axis and z-axis.

$\mathrm{X}$ axis

Markers $121-125$

Total station measure: 0.38 meter

\begin{tabular}{|c|c|c|c|c|c|}
\hline \multirow{2}{*}{ Camera } & $\begin{array}{c}\text { Resolutio } \\
\mathrm{n}\end{array}$ & $\mathrm{fps}$ & $\begin{array}{c}\text { Distance } \\
(\mathrm{m})\end{array}$ & $\begin{array}{c}\text { Diff } \\
(\mathrm{m})\end{array}$ & $\begin{array}{c}\text { Diff } \\
(\mathrm{mm})\end{array}$ \\
\hline Iphone 5s & $1080 \mathrm{p}$ & 30 & 0.64 & 0.16 & 160 \\
\hline \multirow{2}{*}{ Iphone 7+ } & $1080 \mathrm{p}$ & 30 & 0.87 & 0.49 & 490 \\
\cline { 2 - 6 } & $1080 \mathrm{p}$ & 60 & 0.33 & 0.05 & 50 \\
\cline { 2 - 6 } & $4 \mathrm{~K}$ & 30 & 0.30 & 0.08 & 80 \\
\hline Iphone X & $1080 \mathrm{p}$ & 30 & 0.13 & 0.25 & 250 \\
\cline { 2 - 6 } & $1080 \mathrm{p}$ & 60 & 0.30 & 0.08 & 80 \\
\cline { 2 - 6 } & $4 \mathrm{~K}$ & 60 & 0.16 & 0.22 & 220 \\
\hline $\begin{array}{c}\text { Digital } \\
\text { camera } \\
\text { (Casio } \\
\text { Exilim) }\end{array}$ & $720 \mathrm{p}$ & 30 & 1.84 & 1.46 & 1460 \\
\hline $\begin{array}{c}\text { DSLR } \\
\text { (Nikon } \\
\text { D7000) }\end{array}$ & $1080 \mathrm{p}$ & 24 & 1.33 & 0.95 & 950 \\
\hline
\end{tabular}

Table 2. Difference distance in $\mathrm{x}$-axis

The camera calibration result was used to calibrate the model that is obtained from the video and the point clouds generated. For example, if the camera calibration shows the difference in $5 \mathrm{~cm}$ and the model shows the difference more than $5 \mathrm{~cm}$, then the model needs to be calibrated so that the model will follow the distance of camera calibration.

Y axis

Markers 113 - 112

Total station measure: 0.82 meter

\begin{tabular}{|c|c|c|c|c|c|}
\hline Camera & Resolution & fps & $\begin{array}{c}\text { Distance } \\
(\mathrm{m})\end{array}$ & $\begin{array}{c}\text { Diff } \\
(\mathrm{m})\end{array}$ & $\begin{array}{c}\text { Diff } \\
(\mathrm{mm})\end{array}$ \\
\hline Iphone & $1080 \mathrm{p}$ & 30 & 1.75 & 0.74 & 740 \\
\hline \multirow{2}{*}{ Iphone } & $1080 \mathrm{p}$ & 30 & 2.39 & 1.38 & 1380 \\
\cline { 2 - 6 } & $1080 \mathrm{p}$ & 60 & 0.91 & 0.10 & 100 \\
\cline { 2 - 6 } & $4 \mathrm{~K}$ & 30 & 0.73 & 0.28 & 280 \\
\hline \multirow{2}{*}{ Iphone } & $1080 \mathrm{p}$ & 30 & 0.31 & 0.70 & 700 \\
\cline { 2 - 6 } & $1080 \mathrm{p}$ & 60 & 0.84 & 0.17 & 170 \\
\hline $\begin{array}{c}\text { Digital } \\
\text { camera } \\
\text { (Casio } \\
\text { Exilim) }\end{array}$ & $720 \mathrm{p}$ & 30 & 4.80 & 3.79 & 3790 \\
\hline $\begin{array}{c}\text { DSLR } \\
\text { (Nikon } \\
\text { D7000) }\end{array}$ & $1080 \mathrm{p}$ & 24 & 3.39 & 2.38 & 2380 \\
\hline
\end{tabular}

Table 3. Difference distance in y-axis
$\mathrm{Z}$ axis

Markers 125 - 092

Total station measure: 1.01 meter

\begin{tabular}{|c|c|c|c|c|c|}
\hline Camera & Resolution & $\mathrm{fps}$ & $\begin{array}{c}\text { Distance } \\
(\mathrm{m})\end{array}$ & $\begin{array}{c}\text { Diff } \\
(\mathrm{m})\end{array}$ & $\begin{array}{c}\text { Diff } \\
(\mathrm{mm})\end{array}$ \\
\hline Iphone 5s & $1080 \mathrm{p}$ & 30 & 1.43 & 0.61 & 610 \\
\hline Iphone 7+ & $1080 \mathrm{p}$ & 30 & 1.93 & 1.11 & 1110 \\
\cline { 2 - 6 } & $1080 \mathrm{p}$ & 60 & 0.75 & 0.07 & 70 \\
\cline { 2 - 6 } & $4 \mathrm{~K}$ & 30 & 0.66 & 0.16 & 160 \\
\hline \multirow{2}{*}{ Iphone X } & $1080 \mathrm{p}$ & 30 & 0.28 & 0.54 & 540 \\
\cline { 2 - 6 } & $1080 \mathrm{p}$ & 60 & 0.68 & 0.14 & 140 \\
\hline $\begin{array}{c}\text { Digital } \\
\text { camera } \\
(\text { Casio }\end{array}$ & $7 \mathrm{~K}$ & 60 & 0.35 & 0.47 & 470 \\
\hline $\begin{array}{c}\text { Exilim) } \\
\text { DSLR } \\
(\text { Nikon } \\
\text { D7000) }\end{array}$ & $1080 \mathrm{p}$ & 24 & 2.95 & 2.13 & 2130 \\
\hline
\end{tabular}

Table 4. Difference distance in z-axis

\subsection{Data Collection}

Process of video recording of a model was carried out. Each camera recorded the same model by using different resolution and frame per second (fps). The model of study area was a guard house as shown in Figure 4.

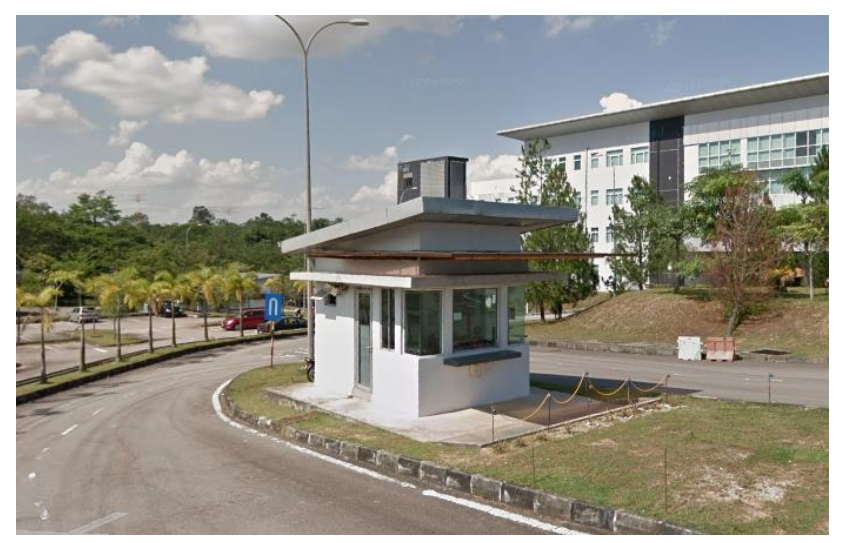

Figure 4. Model of a guard house

The video was recorded around the model. However, there is limitation with EyesCloud3D which is it is still in Beta version, so only 60 seconds of video duration can be processed. In addition, all the features of the model should to be in the camera frame so that there will be no missing features of the model. The video recording should also be taken in the afternoon to avoid any shadow that will appear near the model. Any shadows need to be avoided so that the points cloud that will be generated does not have any shadow point clouds.

\subsection{Processing Video}

In this research the videos are processed by using EyesCloud3D. The result from the processing were in point clouds and mesh of a model. Each camera with different resolution and frame per second (fps) generated different amount of point clouds. If the building is big, therefore the point clouds need to be combined or merged. 


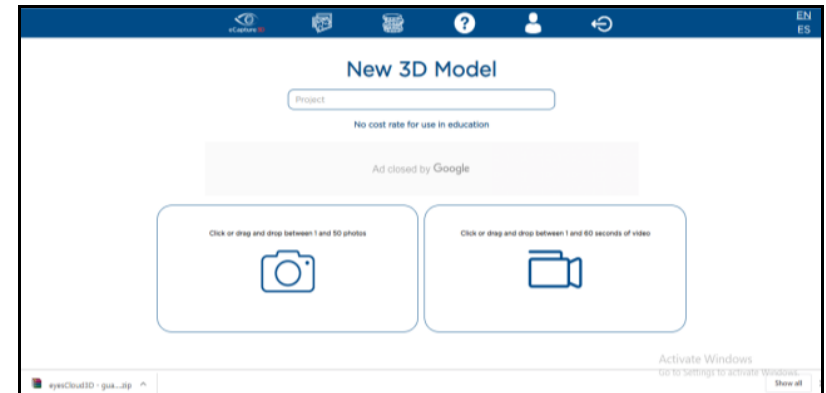

Figure 5. EyesCloud3D a platform to upload video to generate point clouds

The theory to generate point clouds from video is that the video taken holds information about speed and direction. The overlap rate can then be calculated by calculating the distance between adjacent frames using the equation. Next, a rough frame position need to be selected as the anchor point and determine whether the frame meets the requirement of the quality image or not. Once the frame meets the requirement, the ratio is calculated, GRIC value and matching points' number (Zhang, Wang, Li, \& Liu, 2017).

Next to feature point matching, the processing also required an algorithm. The key frames of the video were selected and used as test images. The algorithm was used to detect matching feature points. To remove the exterior point, the method of RANSAC of related basic matrix was used so that the 3D reconstruction can be constructed by following the requirement that they needed (Zhang et al., 2017).

\subsection{D Wireframe Model}

The 3D wireframe model was reconstructed after the point clouds have been generated. AutoCAD Autodesk 2017 software was used for reconstruction of the wireframe model. All the point clouds from different camera, resolution and frame per second (fps) was reconstructed to produce 3D wireframe models. Table 5 shows the 3D wireframe model of each camera according to their resolution and fps.

\begin{tabular}{|c|c|c|c|}
\hline Camera & Resolution & Fps & Model \\
\hline \multirow{3}{*}{ Iphone 5s } & $1080 \mathrm{p}$ & $\begin{array}{c}30 \\
\mathrm{fps}\end{array}$ & \\
\hline \multirow{3}{*}{ Iphone 7+ } & $1080 \mathrm{p}$ & $\begin{array}{c}30 \\
\mathrm{fps}\end{array}$ \\
\cline { 2 - 4 } & $1080 \mathrm{p}$ & $\begin{array}{c}60 \\
\mathrm{fps}\end{array}$ \\
\hline
\end{tabular}

\begin{tabular}{|c|c|c|c|}
\hline & $4 \mathrm{~K}$ & $\begin{array}{l}30 \\
\mathrm{fps}\end{array}$ & 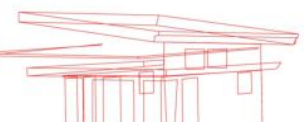 \\
\hline & $1080 p$ & $\begin{array}{l}30 \\
\text { fps }\end{array}$ & 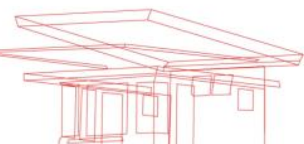 \\
\hline \multirow[t]{2}{*}{ Iphone X } & $1080 p$ & $\begin{array}{l}60 \\
\text { fps }\end{array}$ & $\overline{7 \square}$ \\
\hline & $4 \mathrm{~K}$ & $\begin{array}{l}60 \\
\text { fps }\end{array}$ & $\underline{\overline{t a n}}$ \\
\hline $\begin{array}{l}\text { Digital } \\
\text { Camera } \\
\text { (Casio } \\
\text { Exilim) }\end{array}$ & $720 \mathrm{p}$ & $\begin{array}{l}30 \\
\mathrm{fps}\end{array}$ & 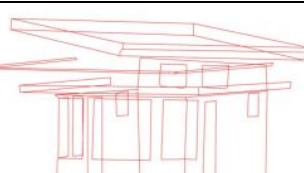 \\
\hline $\begin{array}{l}\text { DSLR } \\
\text { (Nikon } \\
\text { D7000) }\end{array}$ & $1080 \mathrm{p}$ & $\begin{array}{l}24 \\
\text { fps }\end{array}$ & 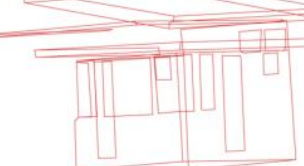 \\
\hline
\end{tabular}

Table 5. 3D wireframe model

\section{EXPERIMENT AND ANALYSIS}

The analysis of camera is carried out to determine which camera has a better quality compare to others. In addition, the analysis can help to identify the application that is suitable according to the total number of point clouds generated from the camera.

The analysis is based on the camera calibration result and total of point clouds generated in EyesCloud3D. The total point clouds and result of calibration shows the quality of the camera.

Table 6 shows the total of point clouds for each camera according to their resolution and frame per second (fps). The higher the total of point clouds, the higher the quality of the camera and the model.

\begin{tabular}{|c|c|c|c|}
\hline Camera & Resolution & Fps & $\begin{array}{c}\text { Number Point } \\
\text { Clouds }\end{array}$ \\
\hline Iphone 5s & $1080 \mathrm{p}$ & $30 \mathrm{fps}$ & $3,789,377$ points \\
\hline Iphone 7+ & $1080 \mathrm{p}$ & $30 \mathrm{fps}$ & $3,500,624$ points \\
\cline { 2 - 4 } & $1080 \mathrm{p}$ & $60 \mathrm{fps}$ & $3,898,404$ points \\
\cline { 2 - 4 } & $4 \mathrm{~K}$ & $30 \mathrm{fps}$ & $4,028,648$ points \\
\hline \multirow{2}{*}{ Iphone X } & $1080 \mathrm{p}$ & $30 \mathrm{fps}$ & $3,874,748$ points \\
\cline { 2 - 4 } & $1080 \mathrm{p}$ & $60 \mathrm{fps}$ & $3,832,829$ points \\
\cline { 2 - 4 } & $4 \mathrm{~K}$ & $60 \mathrm{fps}$ & $3,567,064$ points \\
\hline
\end{tabular}


The International Archives of the Photogrammetry, Remote Sensing and Spatial Information Sciences, Volume XLII-4/W16, 2019 6th International Conference on Geomatics and Geospatial Technology (GGT 2019), 1-3 October 2019, Kuala Lumpur, Malaysia

\begin{tabular}{|c|c|c|c|}
\hline $\begin{array}{c}\text { Digital } \\
\text { Camera } \\
\text { (Casio } \\
\text { Exilim) }\end{array}$ & $720 \mathrm{p}$ & $30 \mathrm{fps}$ & $1,423,320$ points \\
\hline $\begin{array}{c}\text { DSLR } \\
\text { (Nikon } \\
\text { D7000) }\end{array}$ & $1080 \mathrm{p}$ & $24 \mathrm{fps}$ & $3,032,781$ points \\
\hline
\end{tabular}

Table 6. Total number of point clouds

In this analysis result, the total of point clouds of Iphone $7+$ with a resolution of $4 \mathrm{~K} 30 \mathrm{fps}$ is the highest and the second highest is Iphone $7+$ with a resolution of 1080p 60fps. The good result of point clouds can be obtained if the video has a several factors which is consistent lighting, good contrast that will not make the features of the model dark and the distance between the camera with the model, but the distance will not affect too much but the closer the model, the better detail of the features model (Hubber, 2014). However, those factors also can affect the low total number of point clouds and there are the limitation which is in this study, we did not focus on the factors but only the camera specifications of resolution and fps.

The lowest of total point clouds is digital camera with a resolution of 720p 30fps. This is cause of a lower of resolution to compare with other cameras. The second lowest is DSLR with a resolution of $1080 \mathrm{p} 24 \mathrm{fps}$. This is cause of the frame per second (fps) is lower than other cameras. The higher the resolution and fps of certain camera, the total of point clouds will be higher and can get a better detail of the features model. But, when the resolution and fps are higher such as $4 \mathrm{~K} 60 \mathrm{fps}$, the storage and video files will be large to compare with lower resolution and fps. The large video files will filled with noisy, blurry and redundant frames. The higher the frame rate of the camera that not compatible with the camera speed (Rashidi, Dai, Brilakis, \& Vela, 2013), lens imperfections and motion that cannot be control will give a results in motion blur (Rashidi, 2014). In addition, the thing that can cause a problem in generating total of point clouds will be either low speed moving or high speed moving of a camera during recording video (Liu, Tang, \& Ma, 2018).

On the other hand, other camera specifications can also affect the result of total number of point clouds as shown in Figure 6 and Figure 7. But in this research we focus on specifications of resolution and frame per second (fps).

Figure 6 and Figure 7 shows that all the camera specifications that may affect the total number of point clouds. It shows the camera megapixel, main camera specifications, chipset, processor, RAM, iOS and storage of the video taken using the camera according their own resolution and fps.

\begin{tabular}{|c|c|c|c|c|c|c|c|c|c|c|}
\hline $\begin{array}{l}\text { Type of } \\
\text { Camera }\end{array}$ & Resolution & Fps & $\begin{array}{c}\text { Camera } \\
\text { megapixel }\end{array}$ & $\begin{array}{c}\text { Main camera } \\
\text { Specs }\end{array}$ & Chipset & Processor & RAM & IOS & Storage video & $\begin{array}{c}\text { Number Point } \\
\text { Clouds }\end{array}$ \\
\hline Iphone 5s & $1080 \mathrm{p}$ & $\begin{array}{l}30 \\
\mathrm{fps}\end{array}$ & 8 megapixel & $\begin{array}{l}\text { Aperture size: } \\
\text { F2.2; Focal length: } \\
29 \mathrm{~mm} \text {; Sensor } \\
\text { size: } 1 / 3^{\prime \prime} \text {; Pixel } \\
\text { size: } 1.5 \mu \mathrm{m}\end{array}$ & Apple A7 & $\begin{array}{c}\text { Dual-core, } 1300 \\
\text { MHz, Cyclone, } 64- \\
\text { bit, } 28 \mathrm{~nm}\end{array}$ & $1 \mathrm{~GB}$ & $\begin{array}{c}\text { iOS }(10, \\
11)\end{array}$ & $110 \mathrm{MB}$ & $4,352,869$ points \\
\hline \multirow[t]{3}{*}{$\begin{array}{c}\text { Iphone } \\
7+\end{array}$} & $1080 \mathrm{p}$ & $\begin{array}{l}30 \\
\mathrm{fps}\end{array}$ & \multirow{3}{*}{$\begin{array}{c}\text { Dual 12- } \\
\text { megapixel } \\
\text { wide-angle } \\
\text { and } \\
\text { telephoto cam } \\
\text { eras }\end{array}$} & \multirow{3}{*}{$\begin{array}{l}\text { Aperture size: } \\
\text { F1.8; Focal length: } \\
28 \mathrm{~mm} \text {; Sensor } \\
\text { size: } 1 / 3^{\prime \prime} ; \text { Pixel } \\
\text { size: } 1.22 \mu \mathrm{m}\end{array}$} & \multirow{3}{*}{$\begin{array}{c}\text { Apple A10 } \\
\text { Fusion APL } \\
1024\end{array}$} & \multirow{3}{*}{$\begin{array}{l}\text { Quad core (2.34 } \\
\text { GHz, Dual core, } \\
\text { Hurricane + } 1.1 \\
\text { GHz, Dual core, } \\
\text { Zephyr) }\end{array}$} & \multirow{3}{*}{$3 \mathrm{~GB}$} & \multirow{3}{*}{$\begin{array}{c}\mathrm{iOS}(11, \\
12)\end{array}$} & $130 \mathrm{MB}$ & $3,500,624$ points \\
\hline & 1080p & $\begin{array}{l}60 \\
\text { fps }\end{array}$ & & & & & & & $205 \mathrm{MB}$ & 3,898,404 points \\
\hline & $4 \mathrm{~K}$ & $\begin{array}{l}30 \\
\text { fps }\end{array}$ & & & & & & & $399 \mathrm{MB}$ & $4,028,648$ points \\
\hline
\end{tabular}

Figure 6. Other camera specifications 
The International Archives of the Photogrammetry, Remote Sensing and Spatial Information Sciences, Volume XLII-4/W16, 2019 6th International Conference on Geomatics and Geospatial Technology (GGT 2019), 1-3 October 2019, Kuala Lumpur, Malaysia

\begin{tabular}{|c|c|c|c|c|c|c|c|c|c|c|}
\hline \multirow[t]{3}{*}{ Iphone X } & $1080 \mathrm{p}$ & $\begin{array}{l}30 \\
\text { fps }\end{array}$ & \multirow{3}{*}{$\begin{array}{c}\text { Dual 12- } \\
\text { megapixel } \\
\text { wide-angle } \\
\text { and } \\
\text { telephoto cam } \\
\text { eras }\end{array}$} & \multirow{3}{*}{$\begin{array}{c}\text { Aperture size: } \\
\text { F1.8; Focal length: } \\
28 \mathrm{~mm} \text {; Sensor } \\
\text { size: } 1 / 3^{\prime \prime} ; \text { Pixel } \\
\text { size: } 1.22 \mu \mathrm{m}\end{array}$} & \multirow{3}{*}{$\begin{array}{l}\text { Apple A11 } \\
\text { Bionic chip } \\
\text { with Neural } \\
\text { engine }\end{array}$} & \multirow{3}{*}{$\begin{array}{l}\text { Hexa Core (2.39 } \\
\text { GHz, Dual core, } \\
\text { Monsoon + } 1.42 \\
\text { GHz, Quad core, } \\
\text { Mistral) }\end{array}$} & \multirow{3}{*}{$3 \mathrm{~GB}$} & \multirow{3}{*}{$\begin{array}{c}\mathrm{iOS}(11, \\
12)\end{array}$} & $140 \mathrm{MB}$ & 3,874,748 points \\
\hline & $1080 \mathrm{p}$ & $\begin{array}{l}60 \\
\text { fps }\end{array}$ & & & & & & & $256 \mathrm{MB}$ & $3,832,829$ points \\
\hline & $4 \mathrm{~K}$ & $\begin{array}{l}60 \\
\text { fps }\end{array}$ & & & & & & & $836 \mathrm{MB}$ & $3,567,064$ points \\
\hline $\begin{array}{l}\text { Digital } \\
\text { Camera } \\
\text { (Casio } \\
\text { Exilim) }\end{array}$ & $720 \mathrm{p}$ & $\begin{array}{l}30 \\
\text { fps }\end{array}$ & $\begin{array}{c}7.2 \\
\text { megapixel }\end{array}$ & $\begin{array}{c}\text { Aperture size: } 2.8 ; \\
\text { Focal length: } 7.9 \\
\mathrm{~mm}\end{array}$ & & & & & $81.5 \mathrm{MB}$ & $1,423,320$ points \\
\hline $\begin{array}{l}\text { DSLR } \\
\text { (Nikon } \\
\text { D7000) }\end{array}$ & $1080 \mathrm{p}$ & $\begin{array}{l}24 \\
\text { fps }\end{array}$ & $\begin{array}{c}16.2 \\
\text { megapixel }\end{array}$ & $\begin{array}{c}\text { Aperture size: } 3.2 ; \\
\text { Focal length: } 17 \\
\text { mm; Pixel size: } \\
4.78 \mu \mathrm{m}\end{array}$ & & & & & $90.5 \mathrm{MB}$ & $3,032,781$ points \\
\hline
\end{tabular}

Figure 7. Other camera specifications

Furthermore, the visualisation details of the model can be seen using the mesh from the points cloud. If the point clouds are dense, the mesh will be generated smoothly. Table 7 shows the point clouds and mesh of a model.
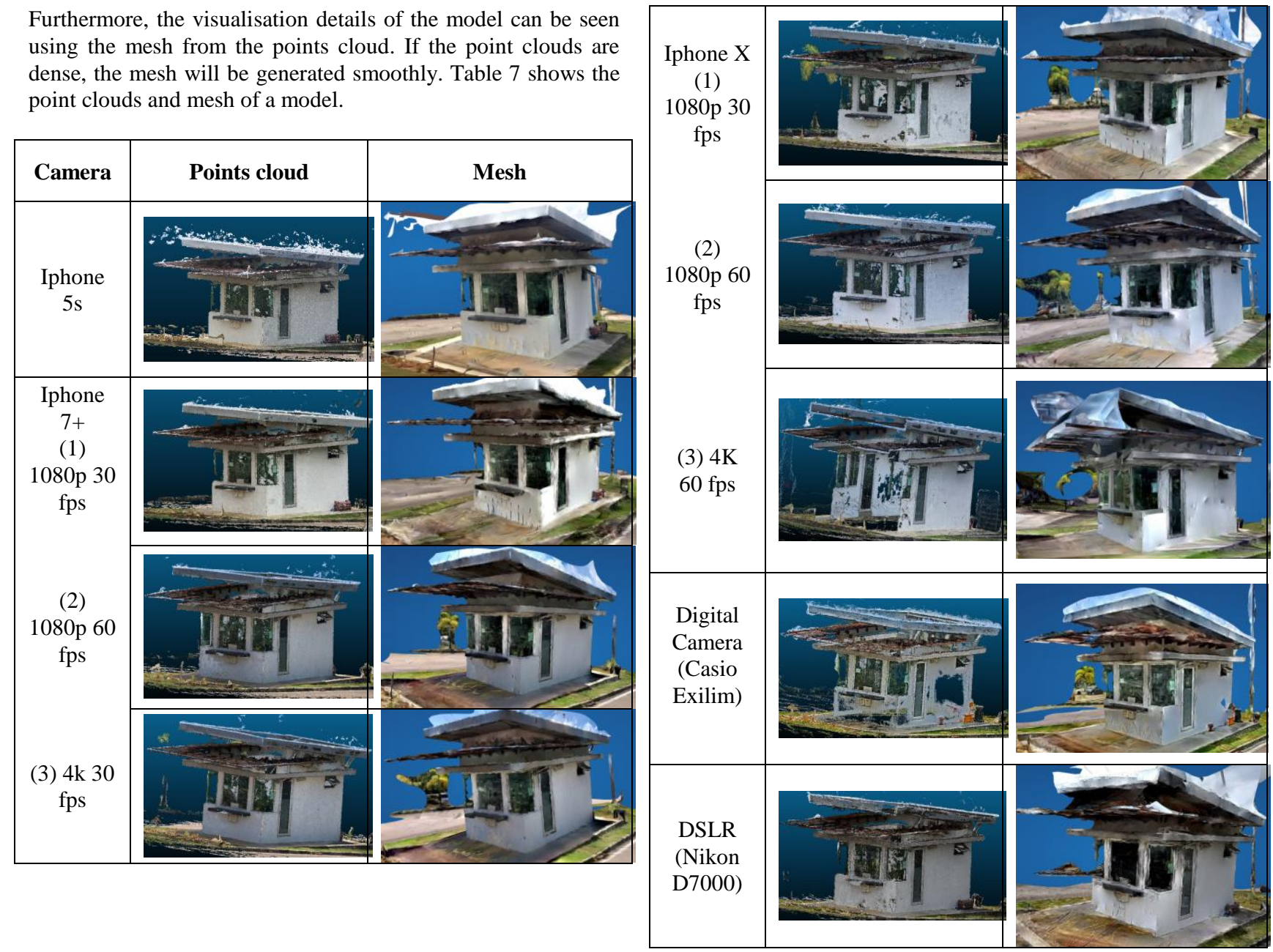

Table 7. Result of point clouds and mesh 
Moreover, there are several applications other than videogrammetry technique that require difference in total of point clouds. Table 8 describes the applications and the total of point clouds that they needed.

\begin{tabular}{|c|c|c|}
\hline Application & $\begin{array}{l}\text { Total Point } \\
\text { Clouds }\end{array}$ & $\begin{array}{l}\text { Camera and Point } \\
\text { Clouds }\end{array}$ \\
\hline $\begin{array}{c}\text { Archaeological } \\
\text { application (Prins, } \\
\text { 2016) }\end{array}$ & 14,859 & $\begin{array}{c}\text { Digital Camera with } \\
720 \text { p 30fps generate } \\
1,423,320 \text { points }\end{array}$ \\
\hline $\begin{array}{c}\text { Videogrammetry } \\
\text { on 3D } \\
\text { reconstruction } \\
\text { from video using } \\
\text { SfM algorithm } \\
\text { (Kurniawan, } \\
\text { Ramdani, \& } \\
\text { Furqon, 2017) } \\
\end{array}$ & 2,910 & $\begin{array}{c}\text { Digital Camera with } \\
720 p \text { 30fps generate } \\
1,423,320 \text { points }\end{array}$ \\
\hline $\begin{array}{l}\text { 3D Modelling of } \\
\text { Headstone by } \\
\text { Low cost } \\
\text { photogrammetry } \\
\text { technique (Landes, } \\
\text { Waton, Alby, } \\
\text { Gourvez, \& Lopes, } \\
\text { 2013) }\end{array}$ & $\begin{array}{c}7,759,342 \\
\text { (PhotoModeler) } \\
2,249449 \\
\text { (PhotoSynth } \\
\text { software) }\end{array}$ & $\begin{array}{l}\text { Camera with } 1080 \mathrm{p} \\
\text { 30fps, 1080p 60fps and } \\
4 \mathrm{~K} \text { 30fps that generate } \\
3 \text { million until } 4 \text { million } \\
\text { points }\end{array}$ \\
\hline $\begin{array}{c}\text { 3D documentation } \\
\text { of contaminated } \\
\text { crime scenes } \\
\text { (Abate, Toschi, } \\
\text { Sturdy-Colls, \& } \\
\text { Remondino, 2017) } \\
\end{array}$ & $3,866,300$ & $\begin{array}{l}\text { Camera with } 1080 \mathrm{p} \\
\text { 30fps and } 1080 \mathrm{p} 60 \mathrm{fps} \\
\text { that generate } 3 \text { million } \\
\text { and above points }\end{array}$ \\
\hline $\begin{array}{c}\text { Reverse } \\
\text { engineering } \\
\text { technique for 3D } \\
\text { modelling of } \\
\text { propellers (Menna } \\
\text { \& Troisi, 2010) } \\
\end{array}$ & $1,400,000$ & $\begin{array}{c}\text { Digital Camera with } \\
720 \text { p 30fps generate } \\
1,423,320 \text { points }\end{array}$ \\
\hline $\begin{array}{c}\text { Assessment of } \\
\text { Building point } \\
\text { clouds (Sirmacek } \\
\text { \& Lindenbergh, } \\
\text { 2014) }\end{array}$ & $\begin{array}{c}230,876 \\
\text { (Iphone) } \\
357,118 \text { (TLS) }\end{array}$ & All cameras \\
\hline
\end{tabular}

Table 8 . Other application with total point clouds and camera specifications' point clouds

The suitable application can be determine based on the camera specification of the resolution and fps and also the total of point clouds generate from the cameras as shown in Table 6. There are several applications with total point clouds from other researches that are listed in Table 8 . From the total point clouds at Table 6 and Table 8, users can determine which cameras are suitable according to the application that they want to do. For example, if the user wants to do 3D in crime investigation, they can use Iphone $5 \mathrm{~s}$, Iphone $7+$ and Iphone $X$ with resolution and fps that can generate point clouds from $3,866,300$ and above.

\section{CONCLUSION}

Videogrammetry technique requires video recording of a model by using camera. The factors that can influence videogrammetry technique is the lighting or weather during recording because it can cause shadow at the model, the contrast of the camera so that the model will not be dark in the video and the distance between the camera and the object. Other factors will be the higher the resolution and frame per second (fps), the higher the total of points cloud that can be generated but also need to consider the large size of video files, the probability for that video to have a blurry, noise and redundant frame will also be high (Rashidi, 2014).

This research studied the quality of the camera based on the result of total point clouds and 3D wireframe model. The whole videogrammetric method starting from recording video, process the video, camera calibration and finally make analysis of the total of point clouds of the camera to determine which camera has a better quality and what application can be used based on the analysis. The resolution and fps of the camera are also of importance in determining the quality of the camera and total of point clouds. In addition, other camera specifications were listed in Figure 6 and Figure 7 which also can affect the result of total number of point clouds.

Due to some limitations, this research only focused on resolution and fps of the camera. Other camera specifications can be analysed for further studies in the future.

\section{ACKNOWLEDGEMENT}

This research was partially funded by UTM Research University Grant, Vot Q.J130000.3552.05G34 and Vot Q.J130000.3552.06G41. This research is also part of the collaboration between 3D GIS Research Lab, UTM and eCapture3D (Ecapture Research and Development SL). eCapture has provided eyescloud3d for this research via their platform www.eyescloud3d.com.

\section{REFERENCES}

Abate, D., Toschi, I., Sturdy-Colls, C., \& Remondino, F. (2017). A low-cost panoramic camera for the $3 d$ documentation of contaminated crime scenes. International Archives of the Photogrammetry, Remote Sensing and Spatial Information Sciences - ISPRS Archives, 42(2W8), 1-8. https://doi.org/10.5194/isprs-archives-XLII-2-W8-1-2017

Azri, S., François, A., Ujang, U., Darka, M., Alias, A.R., 2015. Crisp Clustering Algorithm for 3D Geospatial Vector Data Quantization, Lecture Notes in Geoinformation and Cartography. Springer Verlag, pp. 71-85.

Brilakis, I., Fathi, H., \& Rashidi, A. (2011). Progressive 3D reconstruction of infrastructure with videogrammetry. Automation in Construction, 20(7), 884-895. https://doi.org/10.1016/j.autcon.2011.03.005

González-Jorge, H., Riveiro, B., Arias, P., \& Armesto, J. (2012). Photogrammetry and laser scanner technology applied to length measurements in car testing laboratories. Measurement: Journal of the International Measurement Confederation, 45(3), 354-363. https://doi.org/10.1016/j.measurement.2011.11.010

Hubber, J. (2014). Turn * any * Video into a 3D Model, 3-7. Kurniawan, R. A., Ramdani, F., \& Furqon, M. T. (2017). Videogrammetry: A New Approach of 3-DImensional Reconstruction from Video Using SfM Algorithm., 13-17.

Keling, N., Mohamad Yusoff, I., Lateh, H., Ujang, U., 2017. Highly Efficient Computer Oriented Octree Data Structure and 
Neighbours Search in 3D GIS, in: Abdul-Rahman, A. (Ed.), Advances in 3D Geoinformation. Springer International Publishing, Cham, pp. 285-303.

Landes, T., Waton, M.-D., Alby, E., Gourvez, S., \& Lopes, B. (2013). 3D MODELING OF HEADSTONES OF THE $2^{\text {ND }}$ AND $3^{\text {RD }}$ CENTURY BY LOW COST PHOTOGRAMMETRIC TECHNIQUES. ISPRS International Archives of the Photogrammetry, Remote Sensing and Spatial Information Sciences, XL-5/W2(September), 397402. https://doi.org/10.5194/isprsarchives-xl-5-w2-397-2013

Liu, X., Tang, Y., \& Ma, J. (2018). Accuracy Assessment for the Three-Dimensional Coordinates by High-Speed Videogrammetric Measurement. Journal of Electrical and Computer Engineering, 2018(V). https://doi.org/10.1155/2018/4058205

Menna, F., \& Troisi, S. (2010). Low Cost Reverse Engineering Techniques for 3D Modelling of Propellers. International Archives of Photogrammetry, Remote Sensing and Spatial Information Sciences, XXXVIII, 452-457. Retrieved from http://citeseerx.ist.psu.edu/viewdoc/download?doi=10.1.1.222.2 $611 \&$ rep=rep1\&type $=$ pdf

Mohd, Z.H., Ujang, U., 2016. Integrating Multiple Criteria Evaluation and GIS In Ecotourism: A Review. Int. Arch. Photogramm. Remote Sens. Spatial Inf. Sci. XLII-4/W1, 351354.

Mohd, Z.H., Ujang, U., Choon, T.L., 2017. Heritage House Maintenance using 3D City Model Application Domain Extension Approach. International Archives of the Photogrammetry, Remote Sensing \& Spatial Information Sciences

Prins, A. B. (2016). 3D Modeling for Archaeological Documentation using the JVRP Method to record archaeological excavations with millimeter-accuracy. JVRP White Papers in Archaeological Technology, (September), 26. Retrieved from http://jezreelvalleyregionalproject.com/Prins2016_3D-Modeling-for-Archaeological-

Documentation_Version-3.0.pdf

Rashidi, A. (2014). Improved Monocular Videogrammetry for Generating 3D Dense Point Clouds of Built Infrastructure. Civil and Environmental Engineering, (August).

Rashidi, A., Dai, F., Brilakis, I., \& Vela, P. (2013). Optimized selection of key frames for monocular videogrammetric surveying of civil infrastructure. Advanced Engineering Informatics, 27(2), 270-282. https://doi.org/10.1016/j.aei.2013.01.002

Sharbini, A. I. (2013). Application of Video Mapping System for $3 D$ Building Modelling.

Singh, S. P., Jain, K., \& Mandla, V. R. (2014). 3D Scene Reconstruction from Video Camera for Virtual 3D City Modeling. American Journal of Engineering Research, 3(1), $140-148$.

Sirmacek, B., \& Lindenbergh, R. (2014). Accuracy assessment of building point clouds automatically generated from iphone images. International Archives of the Photogrammetry, Remote Sensing and Spatial Information Sciences - ISPRS Archives,
40(5), 547-552. https://doi.org/10.5194/isprsarchives-XL-5547-2014

Ujang, U., Azri, S., Zahir, M., Abdul Rahman, A., Choon, T.L., 2018. Urban Heat Island Micro-Mapping via 3D City Model. Int. Arch. Photogramm. Remote Sens. Spatial Inf. Sci. XLII4/W10, 201-207.

Zhang, C., Wang, H., Li, H., \& Liu, J. (2017). A fast key frame extraction algorithm and an accurate feature matching method for 3D reconstruction from aerial video. Proceedings of the 29th Chinese Control and Decision Conference, CCDC 2017, 6744-6749. https://doi.org/10.1109/CCDC.2017.7978392

Revised August 2019 